\title{
Can they hack it? Yes they can
}

\author{
A smartphone app for patients to collect and compute home blood pressure readings clinched first \\ prize at the inaugural BMJ hack day last weekend
}

\author{
David Payne editor, bmj.com
}

Can a group of talented young web developers with no connection to the BMJ group or its many products help us create better doctors and deliver a "zero harm NHS" in just 30 sleep deprived hours on the hottest weekend of the year?

How about revolutionising scholarly publishing and ensuring that content commissioned in London is relevant to doctors in developing countries around the world?

Were our "hack teams" warned they would miss not one but two Wimbledon finals? And that as they presented their projects to a team of judges and fellow hackers Andy Murray would be the first British man to win a Wimbledon singles title in 77 years?

These were just a few of the many challenges facing the 13 teams that took part in BMJ's inaugural hack day at the weekend. Indeed, as Murray clinched the top title, the winning team was in the process of unveiling its innovation: a smartphone app for patients to collect and compute home blood pressure readings that follow National Institute for Health and Care Excellence guidance.

NICE recommends ambulatory or home based monitoring if a clinic blood pressure reading is $140 / 90 \mathrm{~mm} \mathrm{Hg}$ or higher. ${ }^{1}$ It suggests taking two consecutive measurements twice daily and at least one minute apart, ideally for seven days. GPs are recommended to discard the measurements taken on the first day at home and to use the average value of all the remaining measurements to confirm a diagnosis.

The winning app, developed by the hackers Andrea Weir and Alok Matta and the GP Anne Marie Cunningham, ${ }^{2}$ who is also a clinical lecturer at the University of Cardiff, impressed the judges with its "simplicity and cheapness" and because it saves GPs from having to calculate averages from numerous slips of paper, reducing the potential for error.

In the "show and tell" session Cunningham said that the app worked by using home based monitors that cost as little as $£ 15$ $(€ 17 ; \$ 22)$ in chemists and supermarkets, rather than the $£ 1500$ ambulatory devices, and automatically calculates average readings to comply with NICE guidance, last updated in 2011.
The app includes a video on how and when to take blood pressure readings at home. A patient adds readings of systolic and diastolic pressure, and the app prevents users from adding wrong values or inputting data again before 60 seconds have elapsed.

It would work offline and across different platforms, Cunningham said, and also included "push notifications" to remind patients that they need to take a reading. The data can be emailed or exported in CSV files or XML.

Cunningham said that the app would help to protect against overdiagnosis. She added that although the data wouldn't automatically go to the GP, she hoped that the app could be adapted to do that in the future. The app could also be adapted for other conditions such as diabetes and asthma that also rely on patients' self management.

The day, organised by Rewired State, which runs hack days for government bodies, private companies, and charities, began on Saturday morning with four challenges from BMJ staff to the hackers, who were given access to the underlying datasets that drive BMJ products such as Best Practice, onExamination, and journal articles. ${ }^{3}$

The hackers were asked to develop ideas aimed at:

- Creating a "zero harm" NHS

- Bringing innovative applications to create better doctors for future healthcare needs

- Developing solutions to "localise" BMJ published materials to make them more relevant to different countries, and

- Revolutionising the scholarly publishing process.

The BMJ judges (chief executive officer Tim Brooks, editor in chief Fiona Godlee, and chief technical officer Sharon Cooper) were joined by Helen Bevan, chief of service transformation at the NHS Institute for Innovation and Improvement, and Geraint Lewis, chief data officer at the NHS. They were asked to select three winners.

In second place was a reward based game aimed at digital medical students that uses BMJ's onExamination obstetrics and 
gynaecology questions, developed by Jon Hilton, Daniel Inniss, Giuseppe Sollazzo, Kaelan Fouwels, and Kush Depala. ${ }^{4}$

Hilton, a medical student, described the project as a way to make revision more collaborative and less solitary. He told his fellow hackers: "Find the fun, and the job's a game."

Players, competing against friends, get a tick if they click the answer to a question correctly. Hilton, who describes himself as a "self confessed geek" on his Twitter profile, said that the technology could also accommodate a doctor joining in to advise on answers.

The idea could also meet BMJ's localisation challenge by testing the translation skills of UK doctors working overseas, by scoring their accuracy in translating certain terms, he added. A third potential use would be to score doctors on their skill at "de-jargonising" BMJ Best Practice text for patients.

The third prototype, ${ }^{5}$ the Open Access Button, responded to the scholarly publishing revolution challenge and built on an existing project by counting the number of times a user hit an internet paywall when trying to access an article. Readers then click on a button, and their location data help to build a real time "map of frustration." An online form captures their professional background and the reasons they need to access the paper.

The team's six members sought ideas from Twitter and used a Research Methods and Reporting paper from the $B M J$ journal to populate a map of denied access. The tool also aims to identify sources where a paper is freely available, perhaps as a pre-print version on an author's personal website.

The judges believed that the tool, besides championing open access publishing models, could also function as a "pester power" resource to persuade librarians to subscribe to a particular journal.

All teams presented their projects clearly and enthusiastically, despite the fact that many hackers had worked until dawn and camped out on the floor in sleeping bags. Many were back at their computers by 8 am.

Visit http://hacks.rewiredstate.org/events/bmj to find out about the other teams' work.

1 Krause T, Lovibond K, Caulfield M, McCormack T, Williams B. Management of hypertension: summary of NICE guidance. BMJ 2011;343:d4891.

2 Weir A, Cunningham AM, Matta A. HBPM diagnosis app. http://hacks.rewiredstate.org/ events/bmj/hbpr-diagnosis-app.

3 Bower C. BMJ web development blog: Ready for BMJ hack this weekend? 4 Jul 2013. http://blogs.bmj.com/bmj-journals-development-blog/2013/07/04/ready-for-bmj-hack-thisweekend/.

4 Hilton J, Inniss D, Sollazzo G, Fouwels K, Depala K. FSO: focussing students on objectives. http://hacks.rewiredstate.org/events/bmj/fso-focusing-students-on-objectives.

5 Open Access Button by Joe, Andy, Florian, Elliot, Nick, Twitter, David (remotely). http:// hacks.rewiredstate.org/events/bmj/open-access-button.

Cite this as: BMJ 2013;347:44437

๑ BMJ Publishing Group Ltd 2013 